\title{
IMPLEMENTASI METODE FUZZY LOGIC UNTUK SISTEM PENGUKURAN KUALITAS UDARA DI KOTA MEDAN BERBASIS INTERNET OF THINGS (IOT)
}

\author{
Jaka Prayudha ${ }^{1}$, Ardianto Pranata ${ }^{1}$, Afdal Al Hafiz $^{1}$ \\ ${ }^{1}$ Sistem Komputer, STMIK Triguna Dharma \\ email: jakaprayudha3@gmail.com
}

\begin{abstract}
Air quality plays an essential role for the life of living creatures on the surface of this earth especially for humans, during this time the decrease of air quality in several cities in the region of Indonesia continues to increase due to several things such as industrial growth and the rapid development of motor vehicles compared to the increasing population increased and not comparable with green open space and green area conservation especially in urban areas. The processing system of the acquisition results obtained from the use of several combinations of sensors (multisensor), ie, sensors that can detect motor vehicle exhaust, dust particles, industrial smoke and oxygen levels in the air. The results of the sensor data acquisition process will then be processed with fuzzy artificial intelligence embedded in a microcontroller chip. This Internet of Things (IoT) based air quality measurement system will be able to be used as a medium for broadcasting air quality-related information in a region, thereby providing a decrease in the health impact for the community who will perform activities outside the home.
\end{abstract}

Keywords: Air quality, multisensory, internet of things, fuzzy

\begin{abstract}
Abstrak: Kualitas udara mengambil peran penting bagi kehidupan mahkluk hidup di permukaan bumi ini terutama untuk manusia, pada masa ini penurunan kualitas udara di beberapa kota di wilayah Indonesia terus meningkatkan diakibatkan beberapa hal diantaranya pertumbuhan industri dan perkembangan kendaraan bermotor yang semakin pesat sebanding dengan pertumbungan penduduk yang makin meningkat dan tidak sebanding dengan pertumbungan ruang terbuka hijau dan pelestarian kawasan hijau khususnya pada wilayah perkotaan. Sistem pemrosesan dari hasil akuisisi yang didapatkan dari penggunaan beberapa kombinasi sensor (multisensor) yaitu sensor yang dapat mendeteksi gas buang kendaraan bermotor, partikel debu, asap dari hasil industri, dan kadar oksigen dalam udara. Hasil dari proses akuisisi data sensor kemudian akan diproses dengan kecerdasan buatan fuzzy yang ditanamkan pada sebuah chip mikrokontroler. Sistem pengukur kualitas udara berbasis Internet of Things (IoT) ini akan dapat digunakan sebagai media penyebar luasan informasi terkait kualitas udara pada suatu wilayah, sehingga akan memberikan penurunan dampak kesehatan bagi masyarakat yang akan melakukan aktivitas diluar rumah.
\end{abstract}

Kata kunci: Kualitas udara, multisensory, internet of things, fuzzy 


\section{PENDAHULUAN}

Kualitas udara mengambil peran penting bagi kehidupan mahkluk hidup di permukaan bumi ini terutama untuk manusia, pada masa ini penurunan kualitas udara di beberapa kota di wilayah Indonesia terus meningkatkan diakibatkan beberapa hal diantaranya pertumbuhan industri dan perkembangan kendaraan bermotor yang semakin pesat sebanding dengan pertumbungan penduduk yang makin meningkat dan tidak sebanding dengan pertumbungan ruang terbuka hijau dan pelestarian kawasan hijau khususnya pada wilayah perkotaan.

Penurunan kualitas udara juga diakibatkan kebakaran hutan di beberapa wilayah Indonesia yang mengakibatkan penurunan kualitas udara semakin buruk yang menyebabkan peningkatan polusi udara dan penurunan kualitas udara segar pada suatu wilayah, hal ini menyebabkan beberapa dampak diantaranya Infeksi Saluran Pernapasan (ISPA) yang mengakibatkan penurunan kemampuan konsentrasi hingga tingkat kematian, dampak buruk bagi kelangsungan makhluk hidup terutama manusia, hal ini dikarenakan masyarakat pada umumnya tidak dapat mendapatkan informasi kualitas udara pada sebuah wilayah dikarenakan tidak memiliki alat ukur. Karena untuk memiliki sebuah alat pengukur kualitas udara dibutuhkan biaya yang cukup mahal bagi penggunaanya.

Penerapan bidang teknologi saat ini dimanfaatkan untuk menurunkan dampak dari penurunan kualitas udara dengan cara memberikan informasi secara luas, cepat dan murah biaya agar manusia mendapatkan informasi terkait kualitas udara di suatu wilayah secara terkini. Sehingga dapat menurunkan dampak buruk bagi kesehatan manusia. Implementasi sistem chip mikrokontroler dapat digunakan sebagai sistem tertanam (system embedded) yang digunakan untuk melakukan pemrosesan dari hasil akuisisi yang didapatkan dari penggunaan beberapa kombinasi sensor (multisensor) yaitu sensor yang dapat mendeteksi gas buang kendaraan bermotor, partikel debu, asap dari hasil industry, dan kadar oksigen dalam udara. Hasil dari proses akuisisi data sensor kemudian akan diproses dengan kecerdasan buatan yang ditanamkan pada sebuah chip mikrokontroler.

Kecerdasan buatan ditanamkan pada sistem pengukur kualitas udara yang dirancang agar sistem dapat berpikir, menalar dan melakukan pengambilan keputusan dalam menentukan kualitas udara pada suatu wilayah. Untuk itu metode fuzzy digunakan dalam membentuk kecerdasan buatan pada sistem pengukur kualitas udara dengan memanfaatkan konsep utama metode fuzzy yaitu kesamaran (keabu-abuan) dalam proses penerimaan informasi yang akan digunakan dalam pengambilan keputusan yang pasti.

Dalam penyebar luasan informasi dari hasil keputusan sistem pengukur kualitas udara dilakukan dengan cepat, mudah dan menghemat biaya dikarenakan dukungan fasilitas internet yang cepat dan terjangkau, apalagi saat ini hampir $60 \%$ penduduk Indonesia telah menggunakan fasilitas internet untuk segala keperluan dalam beraktivitas. Hal ini dapat membantu memberikan informasi terkait kualitas udara dengan pemanfaatan media internet. Sistem pengukur kualitas udara berbasis Internet of Things (IoT) ini akan dapat digunakan sebagai media penyebar luasan informasi terkait kualitas udara pada suatu wilayah, sehingga akan memberikan penurunan dampak kesehatan bagi masyarakat yang akan melakukan aktivitas diluar rumah, karena masyarakat dapat mengetahui kualitas udara yang ada pada lingkungannya dan tujuan wilayah yang akan dikunjunginya. 


\section{METODOLOGI}

\section{Kualitas Udara}

Udara merupakan sebuah atmosfer yang terdapat di sekeliling bumi yang fungsinya untuk memberikan perlindungan pada bumi dari gangguan luar bumi. Udara pada alam tidak sepenuhnya bersih dikarenakan adanya polutan akibat atkivitas manusia. Kualitas udara merupakan paremater untuk mengukur keadaan pada udara yang layak pada sebuah wilayah. Penurunan kualitas udara diakibatkan oleh polutan seperti beberapa jenis gas, asap kendaraan, asap industry dan limbah udara dari rumah tangga. Berikut ini parameter pengukuran kualitas udara berdasrakan dari Indeks Standard Pencemaran Udara (ISPU) (http://iku.menlhk.go.id/)

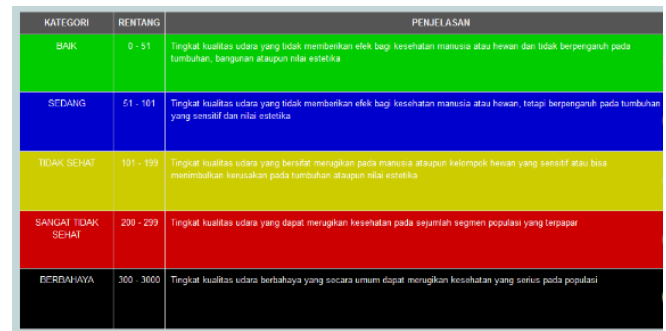

Gambar 1. Kriteria Kualitas Udara

\section{Internet of Things}

Internet merupakan sebuah jaringan komputer yang luas dan terbesar di dunia karena menghubungkan banyak komputer di dunia secara bersamaan. Pemanfaatan internet saat ini dapat dirasakan oleh seluruh lapisan masyarakat diantaranya penyebaran informasi yang luas, cepat dan bebas sehingga masyarakat mendapatkan sebuah informasi dengan mudah. Pengembangan internet menjadi sebuah teknologi Interenet of Things memastikan dapat melakukan pengendalian dan monitoring berbasis internet yang artinya seseorang dapat melakukan pengawasan pada sistem secara jarak jauh, dimanapun dan kapanpun tanpa batas dan akses informasi dapat dibuat secara terbuka (public information) dan secara tertutup (private information). Penerapan Internet of Things (IoT) sejauh ini digunakan pada komunikasi machine to machine (M2M) di bidang sistem kendail, bidang industry, bidang manufaktur dan lainnya. Produk yang berbasis Internet of Things ini lah yang nantinya akan mempermudah seseorang dalam mendapatkan data yang akurat dan cepat berbasis sistem cerdas (smart machine).

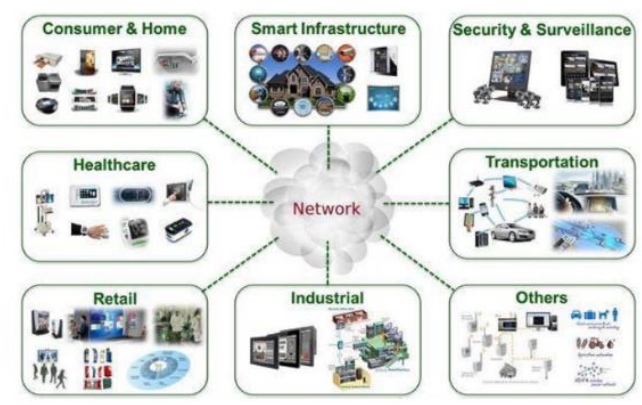

Gambar 2. Konsep Internet of Things

\section{Metode Fuzzy Algoritma Mamdani}

Metode Fuzzy merupakan sebuah metode dengan pemikiran bagaimana dapat menemukan sebuah solusi yang sifatnya samar/abu-abu. Lotfi Zadeh menemukan sebuah konsep logika fuzzy tahun 1964 dengan dasar pemikiran tidak ada keadaan yang yang bernilai "true" or "off". Setiap hasil keluaran sistem pastinya ada nilai gradasi diantara true or off dengan cara melakukan pergeseran skala variable yang dapat diukur sebagai bagian dari true or bagian dari false. Untuk memanfaatkan keadaan tersebut perlun adanya teori himpunan klasik yang berdasrakan pada logika ekstrem yang dapat menetapakan objek sebagai anggota atau bukan anggota himpunan. Pada logika fuzzy suatu objek dapat menjadi anggota pada banyak himpunan dengan derajat keanggotaan yang berbeda pada masing-masing himpunan. Derajat keanggotan pada suatu himpunan memiliki skala 0 sampai 1.

Pelopor aplikasi logika fuzzy 
dalam bidang kontrol, yang merupakan aplikasi pertama dan utama dari logika fuzzy adalah Prof. Ebrahim Mamdani dkk dari Queen Mary College London. Penerapan kontrol logika fuzzy secara nyata di industri banyak dipelopor para ahli dari jepang, misalnya Prof. Sugeno dari Tokyo Institute of Technology. Aplikasi logika fuzzy hampir tak terbatas, misalnya untuk kontrol proses, proses produksi, robotika, manajemen skala besar, teknik sipil, kimia, transportasi, kedokteran maupun ekonomi. Pengaturan (control) sistem non linier yang mengandung sejumlah informasi padat memerlukan pengintegrasian sistem secara cepat dan dapat diterapkan dengan menggunakan logika fuzzy.

Fungsi keanggotaan (membership functions) adalah suatu kurva yang menunjukkan pemetaan titik-titik input data ke dalam nilai keanggotaannya (sering juga disebut dengan derajat keanggotaan) yang memiliki interval dari 0 sampai 1 . Salah satu cara yang dapat digunakan untuk mendapatkan nilai keanggotaan adalah melalui pendekatan fungsi.

1. Fungsi Segitiga

Fungsi ini memiliki satu nilai $\mathrm{x}$ yang memiliki derajat keanggotaan sama dengan 1 , yaitu ketika $\mathrm{x}=\mathrm{b}$. Tetapi, nilai- nilai di sekitar $b$ memiliki derajat keanggotaan yang turun cukup tajam.

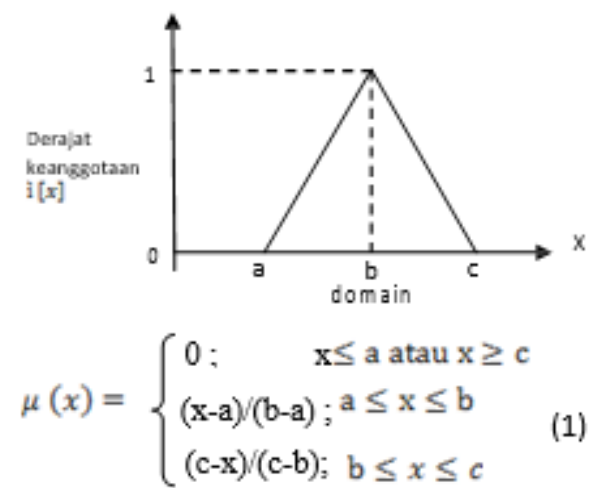

Gambar 3.Fungsi Segitiga
2. Fungsi Trapesium

Fungsi ini terdapat beberapa nilai $\mathrm{x}$ yang memiliki derajat keanggotaan sama dengan 1 , yaitu ketika $\mathrm{b} \leq \mathrm{x} \leq$ c. Tetapi, derajat keanggotaan untuk $\mathrm{a}<\mathrm{x}<\mathrm{b}$ dan $\mathrm{c}<\mathrm{x} \leq \mathrm{d}$ memiliki karakteristik yang sama dengan fungsi segitiga.

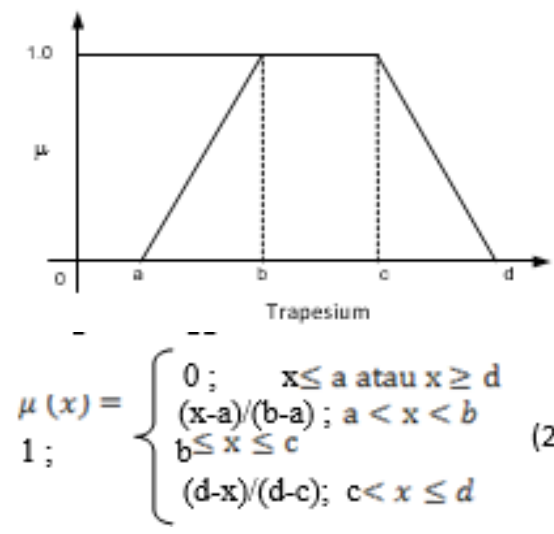

Gambar 4.Fungsi Trapesium

Motivasi utama teori fuzzy logic adalah memetakan sebuah ruang input ke dalam ruang output dengan menggunakan IF-THEN rules. Pemetaan dilakukan dalam suatu Sistem Inferensi Fuzzy (Fuzzy Inference System/FIS) disebut juga fuzzy inference engine adalah sistem yang dapat mengevaluasi semua rule secara simultan untuk menghasilkan kesimpulan dan urutan rule bisa sembarang

Metode Mamdani sering juga dikenal dengan nama Metode Max-Min. Menggunakan MIN pada fungsi implikasi, dan MAX pada komposisi antar fungsi implikasi. Diperkenalkan oleh Ebrahim Mamdani pada tahun 1975. Ada beberapa tahapan yang diperlukan untuk mendapatkan output, adalah sebagai berikut :

1. Pembentukan variable input, himpunan fuzzy, dan output fuzzy. Variabel input maupun variabel output dibagi menjadi satu atau lebih himpunan fuzzy

2. Derjat keanggotaan, Menentukan derajat keanggotaan berdasarkan 
Available online at http://jurnal.stmikroyal.ac.id/index.php/jurteksi

input dan himpunan fuzzy

3. Aplikasi operator fuzzy, Pada tahap ini menentukan $\alpha$-predikat aturan dengan fungsi implikasi MIN dan selanjutnya menentukan nilai dari $\mathrm{Z}$ masing-masing aturan.

4. Penegasan (deffuzy), Input dari proses defuzzifikasi adalah suatu himpunan fuzzy yang diperoleh dari komposisi aturan-aturan fuzzy, sedangkan output yang dihasilkan merupakan suatu bilangan pada domain himpunan fuzzy tersebut. Defuzzifikasi yang digunakan adalah Metode Centroid (Composite Moment), solusi crisp diperoleh dengan cara mengambil titik pusat ( $\left.z^{*}\right)$ daerah fuzzy. Secara umum dirumuskan:

$$
\begin{aligned}
& z=\stackrel{i=0}{n}_{\sum_{i=0}^{n} \mu_{C}\left(z_{i}\right)}^{i+\cdots C^{\prime} i} \\
& z=\frac{\int_{\Re_{1}}^{\Re_{n}} z \mu_{C}(z) d z}{\int_{\Re_{1}}^{\Re_{n}} \mu_{C}(z) d z}
\end{aligned}
$$

5. Mikrokontroler Arduino Uni Rev 3 Arduino uno merupakan sebuah mikrokontroler KIT yang di produksi oleh arduino cooporation yang memiliki tujuan untuk mempermudah para pengembangan sistem cerdas tertanam dalam melakukan pengembangan sistem. Arduino uno berbasis mikrokontroler ATMega 328P dan memiliki 14 pin input/output digital.

Mikrokontroler arduino uno memiliki pin Analog A0-A5 dan memiliki pin Digital 0-13 serta pada pin Digital terdapat pin Pulse Width Modulation (PWM) yang pada umumnya digunakan untuk melakukan kendali pada beragam jenis motor. Penggunaan mikrokon- troler arduino digunakan untuk melakukan akuisisi data sensor berikutnya program yang telah diupload pada mikrokontroler akan melakukan proses sesuai algoritma pemrograman yang diupload.

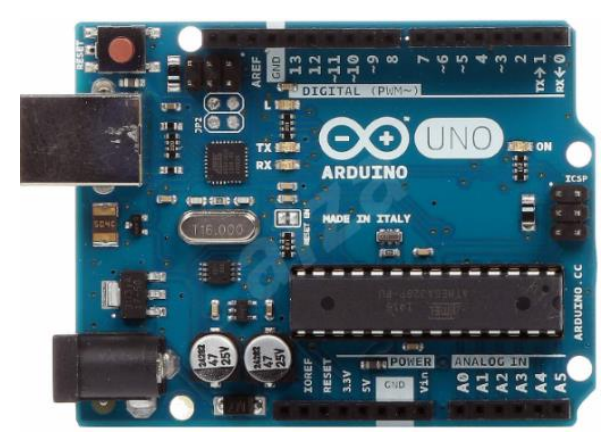

Gambar 2. Arduino Uno

\begin{tabular}{|c|c|}
\hline Microcontroller & ATmega328P \\
\hline Operating Voltage & $5 \mathrm{~V}$ \\
\hline $\begin{array}{l}\text { Input Voltage } \\
\text { (recommended) }\end{array}$ & $7-12 \mathrm{~V}$ \\
\hline $\begin{array}{l}\text { Input Voltage } \\
\text { (limit) }\end{array}$ & $6-20 \mathrm{~V}$ \\
\hline Digital I/O Pins & $\begin{array}{l}14 \text { (of which } 6 \\
\text { provide PWM } \\
\text { output) }\end{array}$ \\
\hline $\begin{array}{l}\text { PWM Digital I/O } \\
\text { Pins }\end{array}$ & 6 \\
\hline Analog Input Pins & 6 \\
\hline $\begin{array}{l}\text { DC Current per } \\
\text { I/O Pin }\end{array}$ & $20 \mathrm{~mA}$ \\
\hline $\begin{array}{c}\text { DC Current for } \\
\text { 3.3V Pin }\end{array}$ & $50 \mathrm{~mA}$ \\
\hline Flash Memory & $\begin{array}{c}32 \mathrm{~KB} \\
(\mathrm{ATmega} 328 \mathrm{P}) \text { of } \\
\text { which } 0.5 \mathrm{~KB} \text { used } \\
\text { by bootloader }\end{array}$ \\
\hline SRAM & $\begin{array}{c}2 \mathrm{~KB} \\
(\mathrm{ATmega328P})\end{array}$ \\
\hline EEPROM & $\begin{array}{c}1 \mathrm{~KB} \\
(\mathrm{ATmega328P})\end{array}$ \\
\hline Clock Speed & $16 \mathrm{MHz}$ \\
\hline LED_BUILTIN & 13 \\
\hline Length & $68.6 \mathrm{~mm}$ \\
\hline Width & $53.4 \mathrm{~mm}$ \\
\hline Weight & $25 \mathrm{~g}$ \\
\hline
\end{tabular}

Tabel 2. Spesifikasi Arduino Uno 
6. Multisensor

Sensor merupakan media transducer yang digunakan untuk melakukan akuisisi (pengambilan) informasi lingkungan dengan menggunakan sebuah mekanisme tertentu. Multisensor merupakan sebuah cara yang digunakan untuk melakukan akuisisi dengan beragam informasi yang diambil seperti suhu, kadar oksigen, kadar gas, kadar asap dan lainnya. Kumpulan data tersebut dideteksi oleh beragam jenis sensor untuk kebutuhan pemrosesan sistem.

\section{HASIL DAN PEMBAHASAN}

Untuk membangun sebuah sistem pengukur kualitas udara berbasis Internet of Things diperlukan beberapa tahapan sebagai berikut:

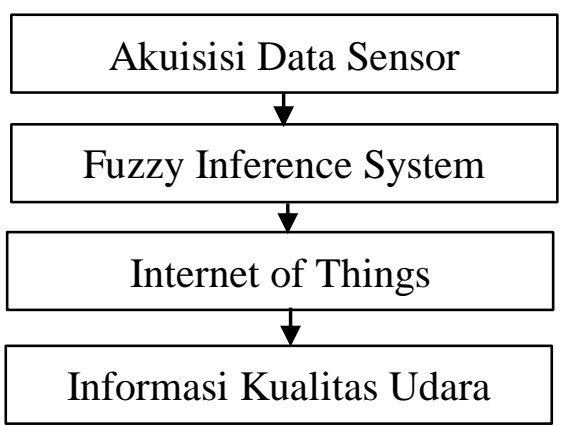

Gambar 3. Algoritma Perancangan Sistem

Terdapat 3 tahapan utama pada sistem pengukuran kualitas udara terdapat tahapan akuisisi data sensor yaitu tahapan pengumpulan data lingkungan dengan beragam jenis sensor, fuzzy inference system (FIS) merupakan sebuah kecerdasan buatan yang ditanamkan kedalam sistem untuk membuat sistem dapat berfikir secara logika dan melakukan pengambilan keputusan secara akurat, internet of things digunakan untuk melakukan transimisi informasi secara luas dengan media internet agar dapat hasil dapat didapatkan secara public, informasi kualitas udara merupakan hasil yang telah diproses oleh mikrokontroler dengan kecerdasan buatan yang tertanam.

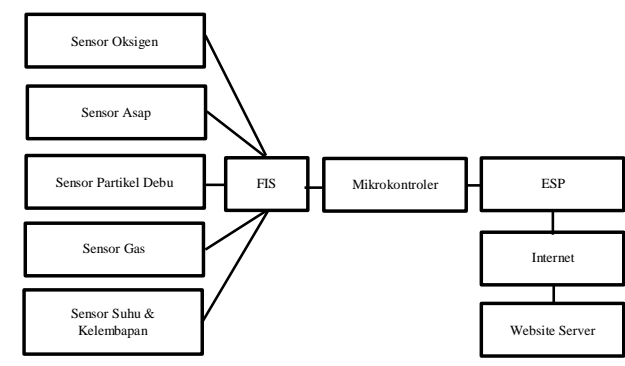

Gambar 4. Blok Diagram Sistem

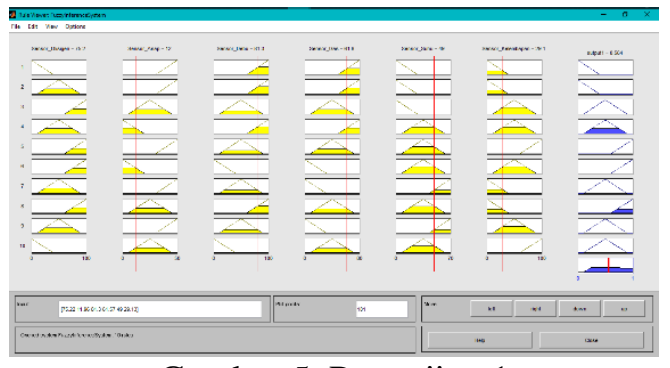

Gambar 5. Pengujian 1

Tabel 3. Pengujian 1

\begin{tabular}{lc}
\hline Data Oksigen & 75.2 \\
\hline Data Asap & 12 \\
\hline Data Debu & 81.3 \\
\hline Data Gas & 61.6 \\
\hline Data Suhu & 49 \\
\hline Data Kelembapan & 29.1 \\
\hline Output & 0.564 \\
\hline Keterangan & Sedang \\
\hline & \\
\hline
\end{tabular}

Gambar 6. Pengujian 2 
Tabel 4. Pengujian 2

\begin{tabular}{lc}
\hline Data Oksigen & 67.4 \\
\hline Data Asap & 21.1 \\
\hline Data Debu & 79.6 \\
\hline Data Gas & 28.9 \\
\hline Data Suhu & 12.5 \\
\hline Data Kelembapan & 10 \\
\hline Output & 0.82 \\
\hline Keterangan & Baik \\
\hline
\end{tabular}

\section{SIMPULAN}

Pada hasil penelitian dilakukan didapatkan hasil yang akurat dengan perbandingan dengan alat ukuran konvensional yang saat ini sering digunakan untuk mengukur parameter ukur kualitas udara. Pada penelitian ini kecepatan dari internet sangat

\section{DAFTAR PUSTAKA}

L. A. Zadeh. (1988). Fuzzy logic. Computer (Long. Beach. Calif). 21(4): 83-93.

M. Logic. (1977). Application of Fuzzy Logic to Approximate Reasoning Using Linguistic Synthesis. IEEE Trans. Comput. C-26(12): 11821191, 1977.

S. N. Sivanandam, S. Sumathi, \& S. N. (2007). Deepa, Introduction to fuzzy logic using MATLAB.

C. C. Lee. (1990). Fuzzy logic in control systems: fuzzy logic controller Part 1. IEEE Transactions On Systems Man And Cybernetics. 20(2): 419-435

E. Cox. (1992). Fuzzy fundamentals. IEEE Spectr. 29(10): 58-61,

N. Kaur, R. Mahajan, D. Bagai, and P. G. Student (2016). Air Quality Monitoring System based on Arduino Microcontroller. Int. J. Innov. Res. Sci. Eng. Technol. (An mempengaruhi web based server dalam melakukan perubahan informasi secara terkini (update), sehingga membutuhkan sebuah jasa layanan internet yang memiliki kecepatan optimal, serta dukungan device server yang cukup agar proses akuisis dan transfer informasi dengan internet tanpa mengalami kendala.

\section{UCAPAN TERIMA KASIH}

Hasil penelitian ini dapat terlaksanakan karena bantuan pendanaan oleh Yayasan Bina Keluarga Sejahtera (YBKS) Melalui STMIK Triguna Dharma serta bantuan dana dari Dinas Kesehatan Kota Medan Melalui Seksi Kesehatan Lingkungan

ISO Certif. Organ., 5(6): 96359646.

C. Kulkarni, S. Grama, P. G. Suresh, C. Krishna, \& J. Antony. (2014). Surveillance Robot Using Arduino Microcontroller, Android APIs and the Internet, in SIMS '14 Proceedings of the 2014 First International Conference on Systems Informatics, Modelling and Simulation. pp. 83-87.

H. Ali-Khodja and L. Aouragh. (2007) Modeling air quality and deposition of trace elements in the vicinity of a cement plant for human health risk assessment. in Water and Soil Quaility Modelling for Risk and Impact Assessment. NATO Security through Science Serie. pp. 141151.

B. Adhikari and S. Majumdar. (2004). Polymers in sensor applications. 
Prog. Polym. Sci. 29(7): 699-766, 2004.

H. Electronic. (2006). Mq-7 Gas Sensor. Carbon Monoxide, 1: 3-5

J. Yick, B. Mukherjee, \& D. Ghosal. (2008). Wireless sensor network survey," Comput. Networks. 52(12): 2292-2330.

D-robotics UK. (2010). Temperature Sensor DHT 11 Humidity \& Temperature Sensor. D-Robotics. pp. 1-9.

a Zanella, N. Bui, a Castellani, L. Vangelista, and M. Zorzi, (2014). Internet of Things for Smart Cities. IEEE Internet Things $J$. 1(1): 22-32,

J. Gubbi, R. Buyya, S. Marusic, and M. Palaniswami. (2013). Internet of Things (IoT): A vision, architectural elements, and future directions. Futur. Gener. Comput. Syst. 29(7): 1645-1660.

C. Perera and A. V. Vasilakos. (2016). A knowledge-based resource discovery for Internet of Things. Knowledge-Based Syst., 109: 122-136.

Mochamad Fajar Wicaksono. (2017). Implementasi Modul Wifi Nodemcu Esp8266 Untuk Smart Home," Jur. Tek. Komputer, UNIKOM, Bandung. 6(1): 1-6

R. K. Kodali and A. Naikoti. (2017). "ECDH based security model for IoT using ESP8266," in 2016 International Conference on Control Instrumentation Communication and Computational Technologies, ICCICCT 2016. pp. 629-633. 